\title{
Behavior and damage of a pipe in the presence of a corrosion defect depth of $10 \%$ of its thickness and highlighting the weaknesses of the ASME / B31G method
}

\author{
H. Berrekia, D. Benzerga \\ University of Sciences and Technology of Oran, Mechanical Department, B.P. 1505, 31000 Oran, Algeria \\ habib.doctorat@hotmail.com,djeb_benz@yahoo.fr
}

\author{
A. Haddi \\ University of Artois, EA 4515, Laboratoire de Génie Civil et géo-Environnement, Béthune F-62400, France \\ abdelkader.baddi@univ-artois.fr
}

\begin{abstract}
The company DRC (pipe repair Department) located within the SONATRACH Company of oil and gas in Algeria, which is responsible for the repair of pipelines for the transport of gas or crude petroleum, will rehabilitate old pipes that have operated on-line for approximately 30 years or come from remaining projects. On the assumption that rehabilitating a pipeline means making it workable under the same conditions as a new structure and reducing the overall cost of the project. The abandonment of these tubes will have an important environmental and financial impact. The rehabilitation, which consists of recovering the maximum of tube, already used, therefore reduces the cost of the project. Inspection and evaluation of corrosion defects are carried out in accordance with ASME/31G method that is applied to low alloyed carbon steels with corrosion defects having soft profiles with low stress concentration.

Our research will consist in developing a method using a behavior-damage coupling of the material to highlight the weaknesses of the ASME / B31G method [1] and show for defects whose depth does not exceed $10 \%$, these defects can survive hydrostatic testing but will develop during service when the pressure is variable.
\end{abstract}

KEYwORDs. Pipeline, Corrosion, Damage Mechanics, Damage, Finite Element Method, Elastoplastic.

\section{OPEN $\bigcirc$ ACCESS}

Citation: Berrekia, H., Benzerga, D., Haddi, A., Behavior and damage of a pipe in the presence of a corrosion defect depth of $10 \%$ of its thickness and highlighting the weaknesses of the ASME / B31G method, Frattura ed Integrità Strutturale, 49 (2019) 643-654.

Received: 03.03.2019

Accepted: 17.06.2019

Published: 01.07.2019

Copyright: (C) 2019 This is an open access article under the terms of the CC-BY 4.0, which permits unrestricted use, distribution, and reproduction in any medium, provided the original author and source are credited.

\section{INTRODUCTION}

$\mathrm{I}$ $\mathrm{n}$ a pipeline project, steel represents more than $35 \%$ of the total cost; the rehabilitation, which consists of recovering the maximum of tube, already used, therefore reduces the cost of the project. On the assumption that rehabilitating a pipeline means making it workable under the same conditions as a new structure and reducing the overall cost of the 
project. By way of example, the rehabilitation of the GZ1 Hassi R'mel-Arzew gas pipeline carried out by DRC / SONATRACH for the SC5-TA section, ie $108 \mathrm{~km}$, was based on a comparative study between two variants:

-Installation of a new line of $108 \mathrm{Km}$ with acquisition of new tubes.

-Reuse of recovered tubes that have already been used for some thirty years of service or from remaining projects and rehabilitated according to the conditions of the ASME / B31G method [1] which confirms the reuse of the tubes at the maximum operating pressure of the gas pipeline at 70 bars.

The example of the gas pipeline GZ1: translates into an overall cost of around $24.892 \mathrm{DA}$ per linear meter for a rehabilitated tube (Tube + Coating + Pose) while if a new section was put the cost would have been $35.065 \mathrm{DA} \mathrm{lm}$. In conclusion, DRC / Sonatrach opts for the first variant which consists in realizing a significant financial saving, ie the use of rehabilitated pipes.

The ASME / B31G method [1] used by DRC / SONATRACH for the determination of the new operating pressure of a corroded pipe assumes that a pipe with a depth of corrosion defect not exceeding $10 \%$ of its thickness can be reused at the operating pressure without any risk and this regardless of the extension and the width of the corrosion defect.

Many researchers have investigated the effect of corrosion and fatigue phenomena on the life-cycle of materials and structures. Based on the visual, metallurgical, and fractographic analyses as well as calculations using established ASME methodologies, Caligiuri has studied the rupture of natural gas pipeline in San Bruno, California [2]. He observed that the failure was caused by the combination of a missing interior weld, a ductile tear, and fatigue cracking.

Zampieri et al. have investigated the influence of the corrosive phenomenon on the fatigue strength of a friction type joint made of high strength preloaded bolts [3]. They observed that the accelerated corrosion process applied to the specimens caused a not negligible reduction of the fatigue strength of joints. These authors have studied the fatigue behaviour of a bolted connection with high strength bolts using finite element method in order to determine the fatigue life cycles of the studied joint. These results suggest that other factors may influence the decrease in fatigue resistance of the corroded connection, such as a variation in the slip coefficient between plates or a certain amount of loss of bolts pretension, which may resulted in a decrease in the friction resistance of the connection and consequently a bearing type behaviour of it [4].

Based on Continuum damage mechanics (CDM), Gabriel Testa et al. [5] have used the Bonora damage model (BDM) to predict the strain limit capacity of X65 steel grade used for pipeline application. it was shown that numerical simulation with CDM could be used to carry on "virtual experiments" for the determination of the material fracture toughness with high degree of accuracy.

Using conventional mathematical methods, B31G, RSTRENG-1, Shell-92, DNV, PCORR, and Fitnet FFS, Terán et al. [6] analyzed a combined corrosion defects, which joins together a general corrosion and a pitting corrosion defects to predict the failure pressure of corroded steel pipelines. It was found that the failure pressure predictions of general corrosion combined with a pit are affected by the length and depth of two corrosion defects.

In our study, we develop constitutive equations taking into account behavior-damage coupling of material to highlight the weaknesses of the ASME / B31G method [1] and show for defects whose depth does not exceed $10 \%$, these defects can survive hydrostatic testing but will develop during service when the pressure is variable [2].

Our research work will focus on developing a method to highlight the weaknesses of the ASME / B31G method [1] and its subsequent modifications. ASME / B31G code is one of the solutions for an assessment of the influence of corrosion defects on pipe integrity. Since it is often regarded as too conservative.

Considering a behavior-damage coupling of the material, finite element numerical simulations were carried out on XC65 steel pipes with pitting in the axial direction. Depending on the size of the corrosion defect (length and width) [3].for a depth equal to $10 \%$ of the pipe wall thickness, the critical or dangerous area where the equivalent Von Mises stress is maximal is determined by the finite element code ANSYS [7]. The calculation of the crack initiation conditions in the critical area is obtained from the history of strain components taken as the output of the finite element calculation.

\section{MODELING}

7 o model the pipeline, we used the ANSYS Workbench 15.0 [7] software with two cases, a model with a rectangular defect and a model with a parabolic defect. Given the symmetry of the pipeline, we modeled a half cylinder. The dimensions of the structure are length, radius and thickness. Thus, we have been able to model the corrosion of the X65 steel pipe taking into account the geometry of the defects, the boundary conditions and the mesh. 


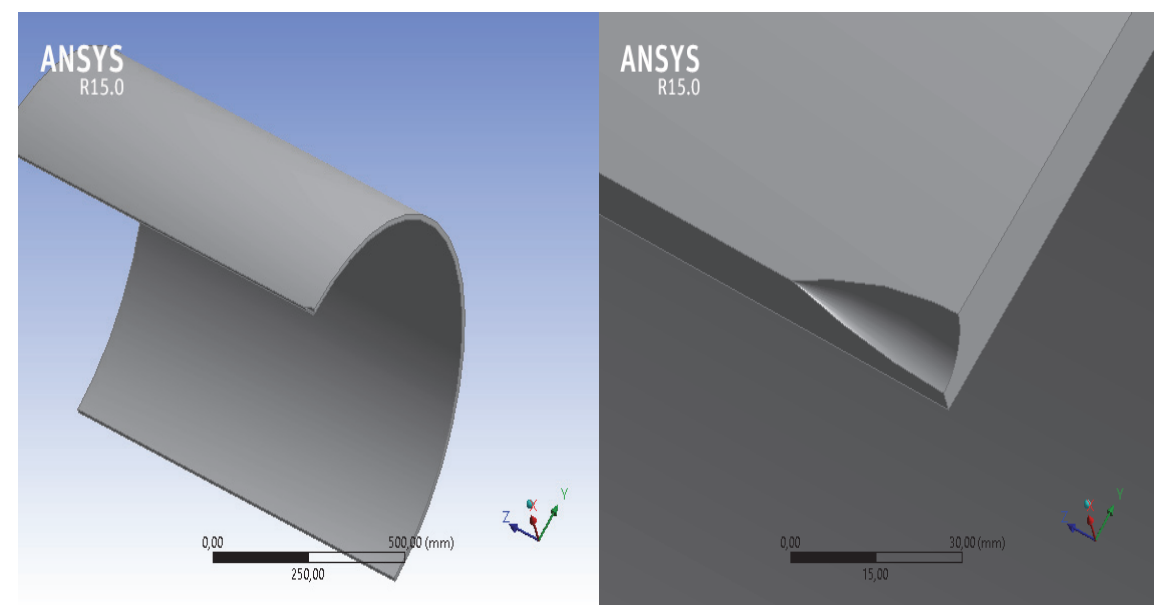

Figure 1: Pipe with elliptic defect.

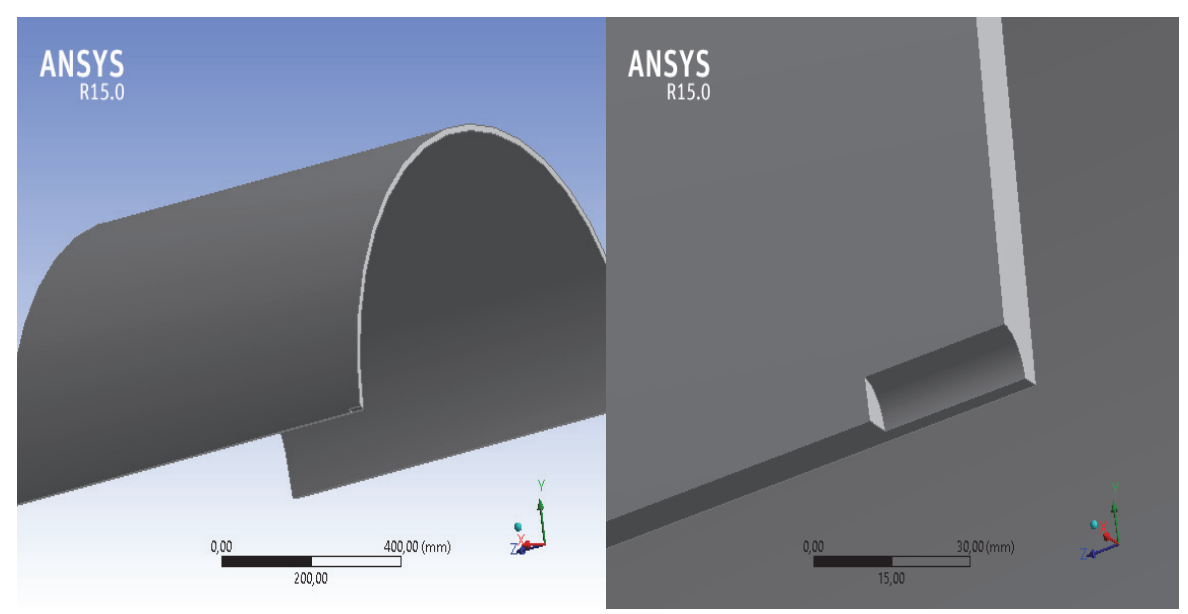

Figure 2: Pipe with rectangular defect.

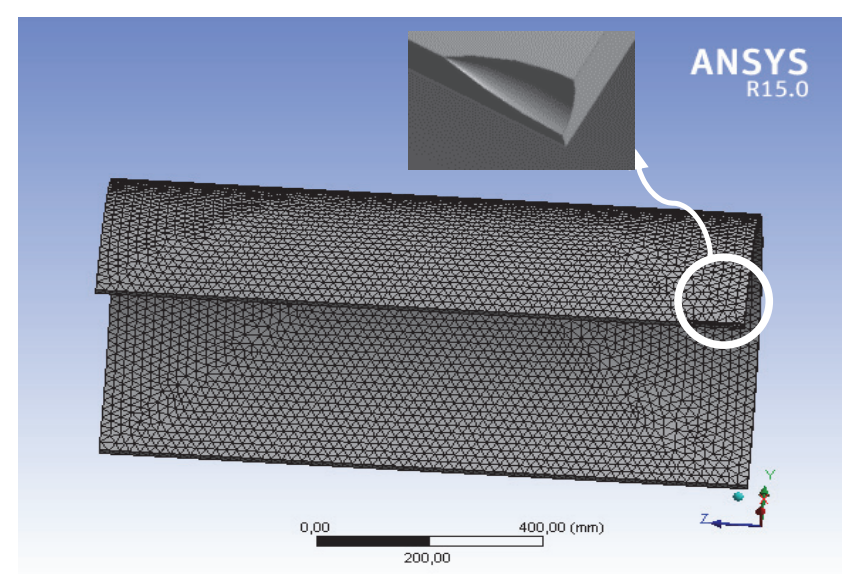

Figure 3: Model with mesh.

Using the programmable language ANSYS [7], a subroutine was developed and implemented in the main code for the determination of critical point $\left(\mathrm{M}^{*}\right)$ in the zone of corrosion defect (see figure 4) where microcracks may grow [8].

Next, the constitutive law of the critical point $\left(\mathrm{M}^{*}\right)$ where the equivalents stress $\sigma^{*}$ is maximum, obtained using the ANSYS code [7], and is implanted in the post- processor based on the Newton iterative method [9].

The study was conducted on pipes of external diameter of 40 " and a thickness of $12.7 \mathrm{~mm}$ in steel X65 whose mechanical properties are grouped in the table $1[10]$. 

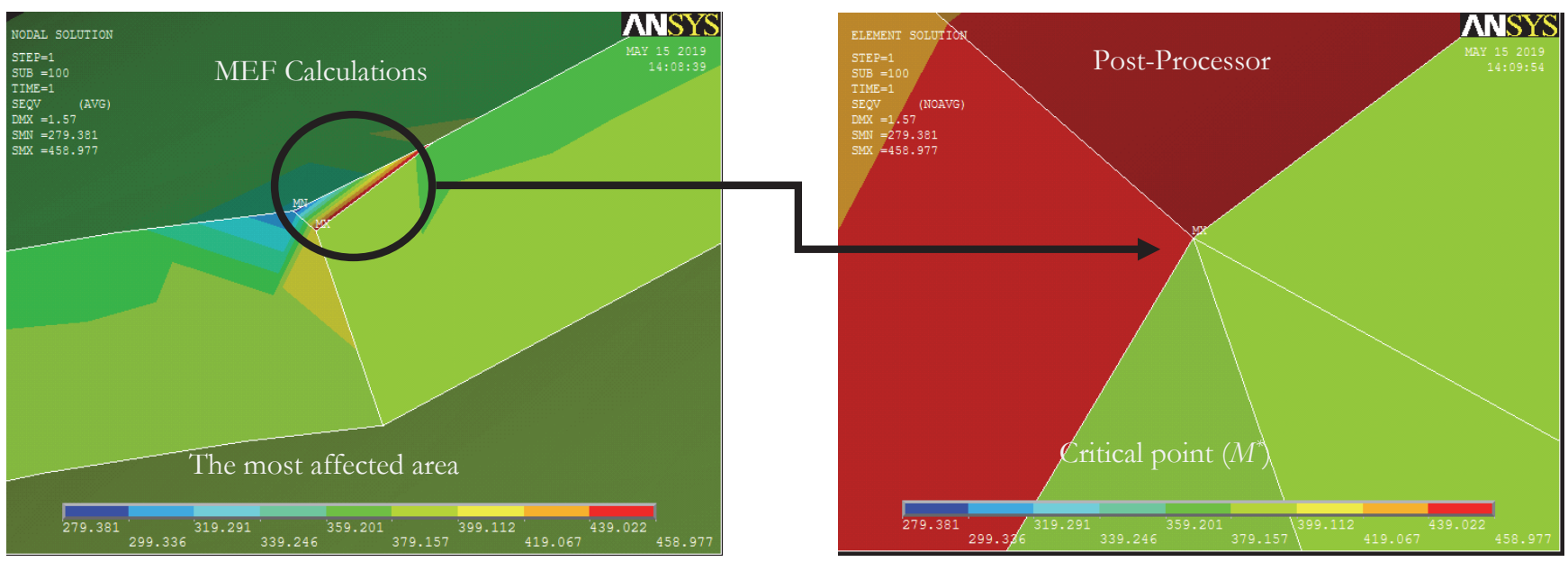

Figure 4: Analysis of local coupling of crack initiation.

\begin{tabular}{lllll}
\hline Young's modulus & Poisson's ratio & Yield strength & Tensile strength \\
$210.7 \quad(\mathrm{GPa})$ & 0.3 & $464.5 \quad(\mathrm{MPa})$ & $563.8 \quad(\mathrm{MPa})$ \\
\hline
\end{tabular}

Table 1: mechanical properties of X65 steel.

To highlight the effect of the width of the defect, we selected the following corrosion defects with a constant depth $\mathrm{d} / \mathrm{t}$ $=10 \%$. The table 2 Bellow groups the defects retained.

\begin{tabular}{lccc}
\hline Defect of corrosion & $\begin{array}{c}\text { Extension }[\mathrm{L}] \\
\mathrm{mm}\end{array}$ & $\begin{array}{c}\text { With [C] } \\
\mathrm{mm}\end{array}$ & $\begin{array}{c}\text { Depth [d] } \\
\mathrm{mm}\end{array}$ \\
Defect -5 & 5 & 5 & 1.27 \\
Defect -10 & 10 & 10 & 1.27 \\
Defect -15 & 15 & 15 & 1.27 \\
Defect -20 & 20 & 20 & 1.27 \\
Defect -25 & 25 & 25 & 1.27 \\
Defect -30 & 30 & 30 & 1.27 \\
Defect -35 & 35 & 35 & 1.27 \\
Defect -40 & 40 & 40 & 1.27 \\
Defect -45 & 45 & 45 & 1.27 \\
Defect -50 & 50 & 50 & 1.27 \\
\hline
\end{tabular}

Table 2: the defects retained.

The graph (see Figure 5) shows the variation of the maximum Von Mises equivalent stress as a function of the extension of the corrosion defect. We note the graphs of all the defects are superimposed this explains the almost negligible effect of the width on the behavior of the corroded pipe. This can be explained by the fact that the depth of the corrosion defect is 
low. There is also a relaxation of the stress of Von Mises from an extension of the defect of $15 \mathrm{~mm}$. From this value the defect of corrosion begins to lose its acuity, there is less stress concentration in the vicinity of the defect.

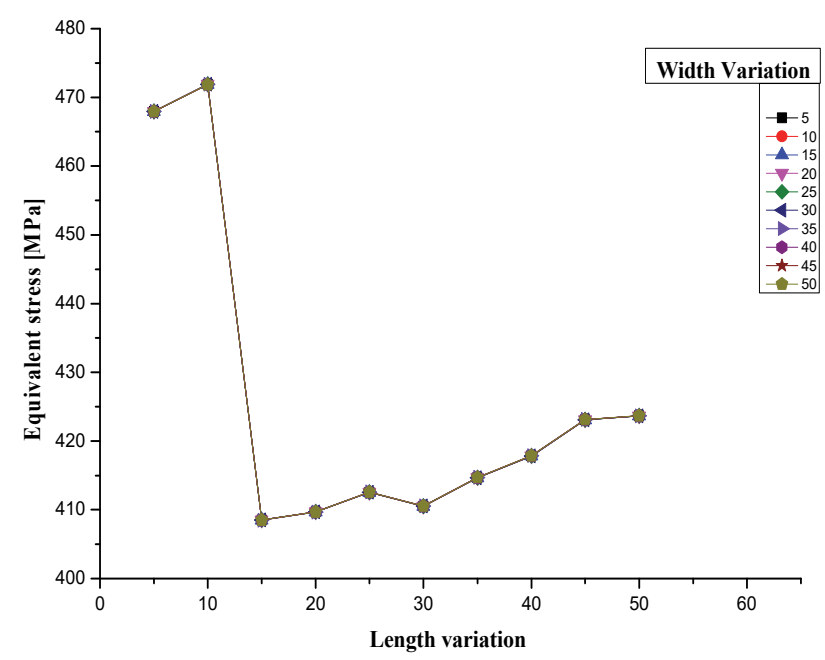

Figure 5: Equivalent stress variation of maximum Von Mises as a function of the length of the corrosion defect.

For the hydrostatic test, the test pressure has been increased until 1.5 times the service pressure according to the standards. Each pipe with its corresponding corrosion defect (extension, width and depth fixed at 10\% of the pipe thickness of $1.27 \mathrm{~mm}$ (see Table 3 below) was subjected to the pressure of the hydrostatic test with a lifetime. The objectif is to determine whether corroded pipes with a depth equal to $10 \%$ of the thickness of the pipe can survive the hydrostatic test and consequently the service pressure.

\begin{tabular}{llll}
\hline & $\begin{array}{l}\text { Extension }[\mathrm{L}] \\
\mathrm{mm}\end{array}$ & $\begin{array}{l}\text { Width[C] } \\
\mathrm{mm}\end{array}$ & $\begin{array}{l}\text { Depth [d] } \\
\mathrm{mm}\end{array}$ \\
Defect -5 & 5 & 5 & 1.27 \\
Defect -10 & 10 & 10 & 1.27 \\
Defect -20 & 20 & 20 & 1.27 \\
Defect -25 & 25 & 25 & 1.27 \\
Defect -35 & 35 & 35 & 1.27 \\
Defect -45 & 45 & 45 & 1.27 \\
Defect -60 & 60 & 60 & 1.27 \\
Defect -65 & 65 & 65 & 1.27 \\
Defect -75 & 75 & 75 & 1.27 \\
Defect -95 & 95 & 95 & 1.27 \\
\hline
\end{tabular}

Table 3: corrosion defect of each pipe

The Figure 6 represents the maximum Von Mises stress as a function of the tangential deformation in the vicinity of the corrosion defect. It clearly shows the behavior of all the corroded pipes exhibiting no damage during the hydrostatic test, which confirms and supports the ASME / B31G method which states that a pipe with a defect whose depth does not exceed $10 \%$ of its thickness, can be reused at the same service pressure without any risk of damage. 


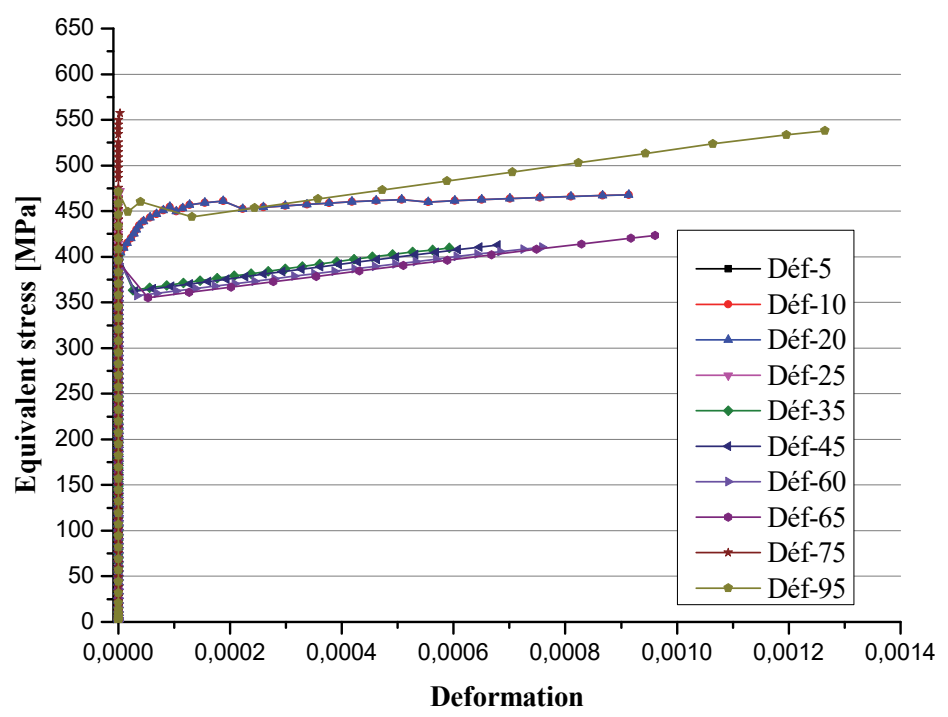

Figure 6: Behavior of corroded pipes during hydrostatic test.

The internal pressure of the gas fluctuates according to the gas demand (see Figure 7), therefore undergoes variations which causes the phenomenon of fatigue. Fatigue is an insidious phenomenon because of its hidden nature can cause breaks for stress levels well below the limit of elasticity.

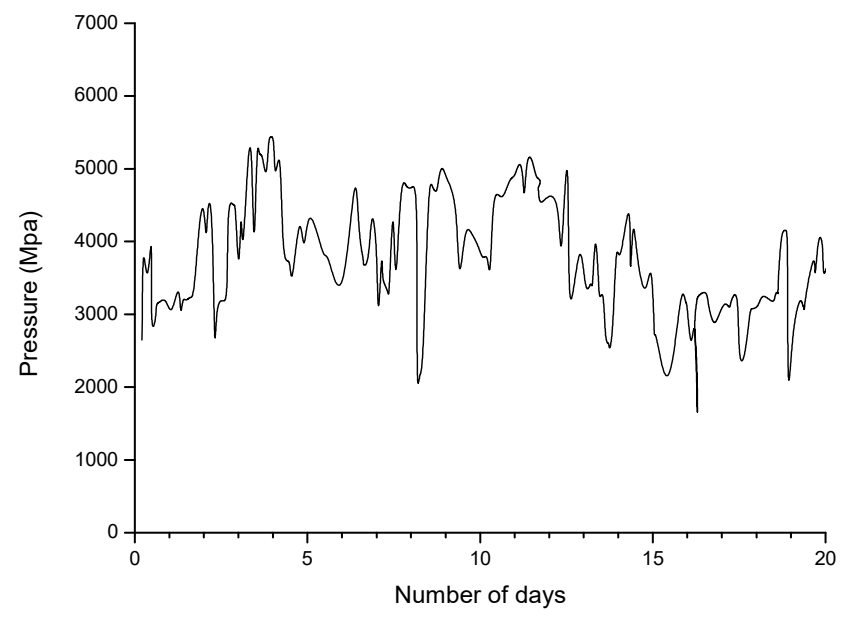

Figure 7: Variation in service pressure as a function of time [11].

Note that during service the pipe can be damaged this is explained by the fact that the phenomenon of fatigue is insidious because of its hidden nature. The rupture can occur for stress values well below the yield point since the fatigue limit is always below the yield point. Fatigue is a phenomenon characterized by a strong micro plasticity in the vicinity of micro defects (micro voids, inclusions, precipitates) that are potential sources of damage.

\section{Behavior - Damage Coupling}




$$
D=\frac{\delta s_{D}}{\delta s}
$$

If the damage is isotropic, $\mathrm{D}$ is a scalar; this allows the introduction of the notion of the effective stress:

$$
\tilde{\sigma}=\frac{\sigma}{1-D}
$$

By considering the principle of deformation equivalence [13], the coupling deformation damage is done at two levels:

$>$ At the level of the elastic potential $\Psi\left(\mathrm{E}^{\mathrm{e}}, \mathrm{D}\right)$ which leads to the law of elasticity of the damaged material :

$$
\sigma=\rho \frac{\partial \Psi}{\partial E^{e}} \text { Or } \quad \mathrm{E}_{\mathrm{ij}}^{\mathrm{e}}=\frac{1+v}{E} \times \frac{\sigma_{\mathrm{ij}}}{1-\mathrm{D}}-\frac{v}{E} \times \frac{\sigma_{\mathrm{IJ}} \cdot \delta_{I J}}{1-\mathrm{D}}
$$

Where E is Young's modulus, and $v$, Poisson's ration.

The associated variable to $D$ is defined by:

$$
\mathrm{Y}=\rho \frac{\partial \Psi}{\partial D} ; \overline{\mathrm{Y}}=-\mathrm{Y}=\frac{\sigma_{e q}^{2}}{2 E} \times \frac{\mathrm{R}_{V}}{(1-D)^{2}}
$$

$\mathrm{Y}$ is the strain energy density release rate [14] defining the power dissipated in the damaging process

where:

$$
\left\{\begin{array}{c}
\sigma_{e q}=\left(\frac{3}{2} \sigma_{i j}^{D} \sigma_{I J}^{D}\right) \\
\mathrm{R}_{V}=\frac{3}{2}(1+v)+3(1-2 v)\left(\frac{\sigma_{H}}{\sigma_{e q}}\right) \\
\sigma_{i j}^{D}=\sigma_{i j}-\sigma_{H} \delta_{i j}
\end{array}\right\}
$$

with:

$$
\sigma_{H}=\frac{1}{3} \sigma_{K K}
$$

At plastic yield function:

$$
f=\frac{\sigma_{e q}}{1-D}-\sigma_{S}
$$

Where: $\sigma_{s}$ is the threshold of plasticity (defined previously).

The condition $\sigma_{e q}<\sigma_{s}$ deviates any plastic deformation and ensures a pure elastic deformation

The zone in the vicinity of the corrosion defect (whose plasticity threshold $\sigma_{S}$ ) undergoes a plastic deformation, therefore a damage, while the zones further from the corrosion defect (whose elastic limit is $\sigma_{y}$ ) undergo only one elastic deformation.

The kinetic law of damage for ductile damage derives from the dissipation potential F [15]: 


$$
F=f+\frac{\mathrm{Y}^{2}}{2 E S(1-D)} H\left(p-p_{0}\right)
$$

$$
\text { where: }\left\{\begin{array}{l}
\text { S: is a constant characterizing the damage, depends on the material and the temperature. } \\
\text { H: Heavyside function. } \\
p_{0}: \text { is the accumulated plastic strain, when the damage is zero (the threshold of damage) } \\
H\left(p-p_{0}\right)=0 \text { If: } \sigma_{e q}<\sigma_{s} \\
H\left(p-p_{0}\right)=0 \text { If: } p \geq p_{0}
\end{array}\right.
$$

The normality rule provides the evolution laws of:

$$
\left\{\begin{array}{l}
E^{p}=\frac{\partial F}{\partial \sigma} \lambda \\
D=-\frac{\partial F}{\partial \sigma} \lambda=\frac{Y}{S} P . H\left(p-p_{0}\right)
\end{array}\right.
$$

Where. $\left\{\begin{array}{l}\lambda \text { : is the plastic multiplier, determined by the consistency condition } f=\dot{f}=0 \\ \text { P. is the accumulated plastic strain }\left(p=p_{0} \text { if } \mathrm{D}=0\right)\end{array}\right.$

With:

$$
\mathrm{P}: \text { is the accumulated plastic strain }\left(p=p_{0} \text { if } \mathrm{D}=0\right)
$$

$$
\mathrm{P}=\left(\frac{2}{3} \mathrm{E}_{i j}^{p} \mathrm{E}_{i j}^{\mathrm{P}}\right)^{\frac{1}{3}}
$$

The damage evolution law (7.b) can be written:

$$
D=\frac{\mathrm{Y}}{S} \mathrm{P} \text { If } p \geq p_{0}
$$

When replacing $\mathrm{Y}$ by its value of (4) we obtain:

$$
D=\frac{\sigma_{e q}^{2}}{2 \mathrm{E} S(1-D)^{2}}\left[\frac{2}{3}(1+v)+3(1-2 v)\left(\frac{\sigma_{H}}{\sigma_{e q}}\right)^{2}\right] \mathrm{P}
$$

In summary, the constitutive laws written for Newton's numerical method [16]:

$$
\begin{aligned}
& \mathrm{E}=\mathrm{E}_{i j}^{e}+\mathrm{E}_{i j}^{p} \\
& \begin{array}{|l|l|}
\hline \downarrow & \downarrow
\end{array} \\
& \mathrm{E}_{i j}^{e}=\frac{1+v}{\mathrm{E}} \times \frac{\sigma_{i j}}{1-D}-\frac{v}{\mathrm{E}} \times \frac{\sigma_{k k}}{1-D} \delta_{i j} \quad \mathrm{E}_{i j}^{p}=\frac{3}{2} \times \frac{\tilde{\sigma}_{i j}^{D}}{\sigma_{e q}} \mathrm{P} \mathrm{Si}: \quad f=\dot{f}=0
\end{aligned}
$$

With:

$$
D=\frac{\sigma_{e q}^{2}}{2 \mathrm{E} S} R_{\nu} \mathrm{P} \quad \text { If: } p \geq p_{0}
$$


Using a stepwise method simultaneously with the method (scheme) implicit Newton, which ensures good convergence [17]. The method developed above gives versus of the internal pressure of the pipe, the value of the damage, and the accumulated plastic strain and stress components at each instant until a macroscopic crack initiation at the defect corrosion. This allows determining the maximum lifetime that a corroded pipe could support in the case of a longitudinal corrosion defect. The maximum lifetime is the lifetime value corresponding to the critical value of the damage $\mathrm{D}_{\mathrm{C}}$ (corresponding to crack initiation).

Figure 8 shows the damage as a function of cycles number for retained corrosion defects. It is noted that the damage is initiated in the material for a number of cycles equal to $\mathrm{N}_{0}$ (microscopic crack initiation) and the microcrack propagates until a macroscopic crack is obtained for a number of cycles equal to $\mathrm{N}_{\mathrm{R}}$. Figure 8 also highlights the effect of the degree of corrosion (extension and width of the defect) on the pipe lifetime.

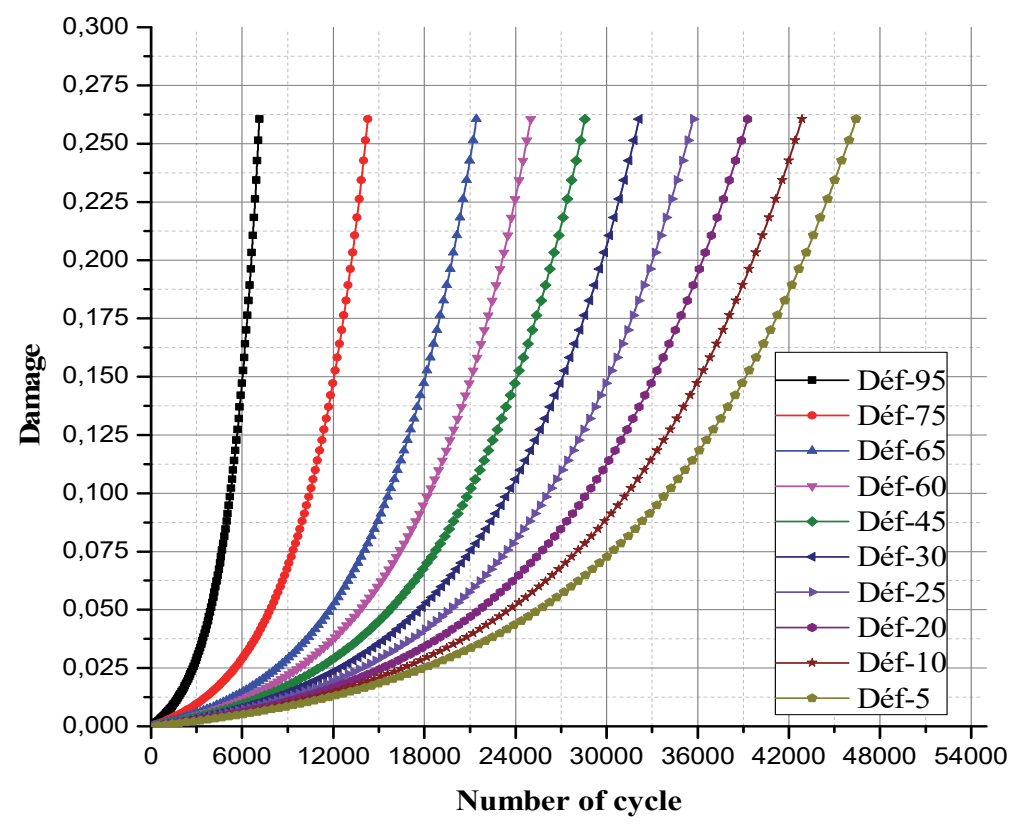

Figure 8: Damage as a function of cycles number.

Based on Figure 6, we can transform the numbers of cycles in lifetime, that is to say in number of days or years knowing that: 1 cycle $=10$ days

\begin{tabular}{lllll}
\hline & \multicolumn{2}{l}{ Cycles number } & \multicolumn{2}{l}{ Days number } \\
Defect & $\mathrm{N}_{0}$ & $\mathrm{Nr}$ & $\mathrm{N}_{0}$ & $\mathrm{Nr}$ \\
Defect-95 & 44 & 7143 & 440 & 71430 \\
Defect-75 & 88 & 14286 & 880 & 142860 \\
Defect-65 & 132 & 21429 & 1320 & 214290 \\
Defect-60 & 154 & 25000 & 1540 & 250000 \\
Defect-45 & 176 & 28572 & 1760 & 285720 \\
Defect-30 & 198 & 32143 & 1980 & 321430 \\
Defect-25 & 220 & 35715 & 2200 & 357150 \\
Defect-20 & 242 & 39286 & 2420 & 392860 \\
Defect-10 & 264 & 42858 & 2640 & 428580 \\
Defect-5 & 286 & 46429 & 2860 & 464290 \\
\hline
\end{tabular}

Table 4: Number of cycles according to corrosion defect. 


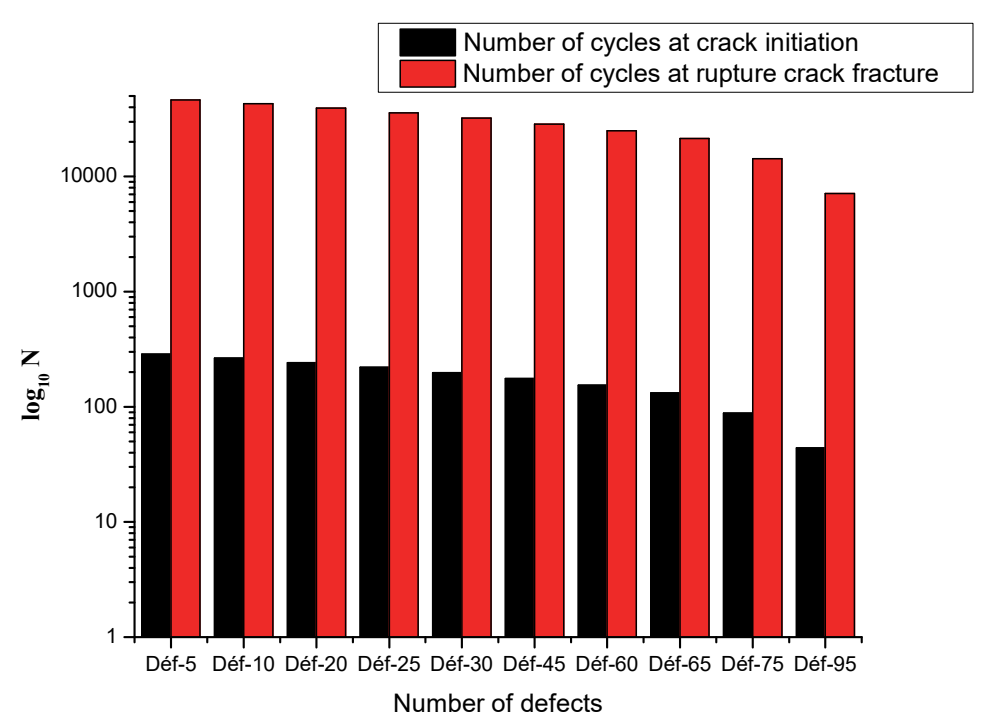

Histogram: service life according to degree of corrosion (extension, width)

The histogram groups the results of the lifetime obtained in number of cycles for each corrosion defect. The investigated pipeline has an initial cycle number $\mathrm{N}_{0}$ of which the damage has appeared (initiation of crack). On the other hand, the pipeline considered can go up to a number NR of cycle (the maximum lifetime) related to the damage causing a rupture. It can be seen that the lifetime $\mathrm{N}_{0}$ at crack initiation or $\mathrm{N}_{\mathrm{R}}$ at failure decrease when the extension and the width of the defect increase keeping a constant depth equal to $10 \%$ of the thickness of the pipe. It is also noted that the lifetimes increase in the case where the extension of the defect is important this can be explained by the increase in the loss of metal and the increase in the volume of the corrosion defect. This shows the effect of the extension of the corrosion defect on the lifetime of the pipe in the case where the depth remains low. The effect of the width of the defect remains negligible for a depth of the defect equal to $10 \%$ of the pipe thickness.

Figure 9 shows the cycle variation at initiation as a function of the length and width of the corrosion defect during pipe service. It is noted that the lifetime at the initiation of a crack in the vicinity of the corrosion defect decreases when the length and width of the defect increase.

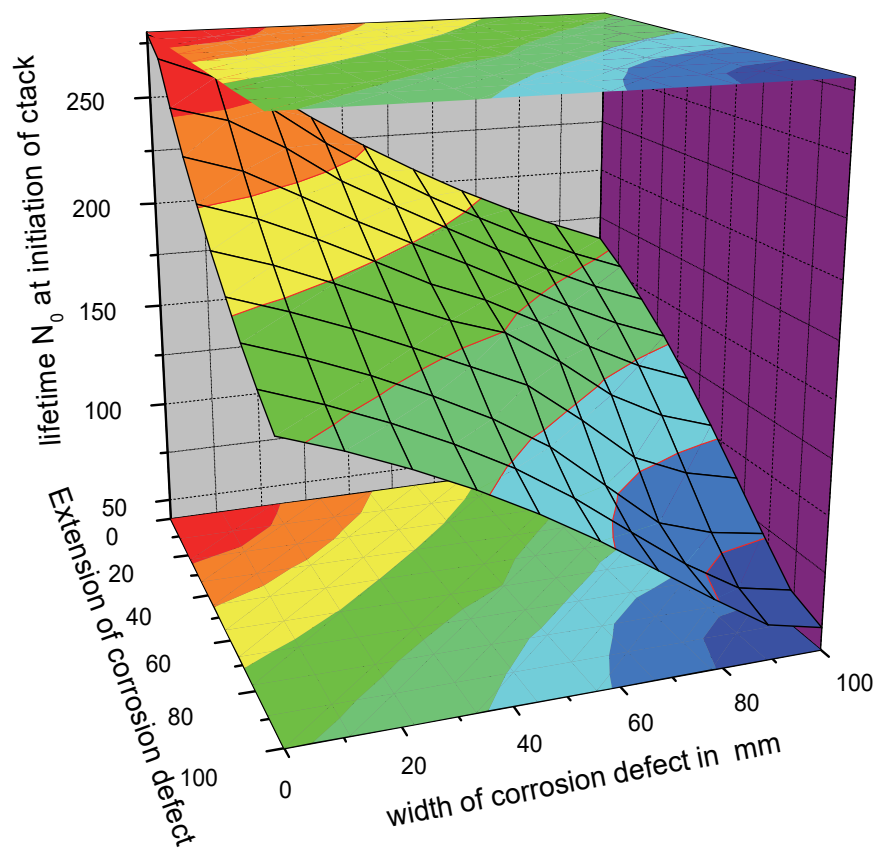

Figure 9: Number of cycles at initiation. 
Figure 10 shows the cycle variation at rupture as a function of the length and width of the corrosion defect during pipe service. It is noted that the lifetime at rupture in the vicinity of the corrosion defect decreases when the length and width of the defect increase.

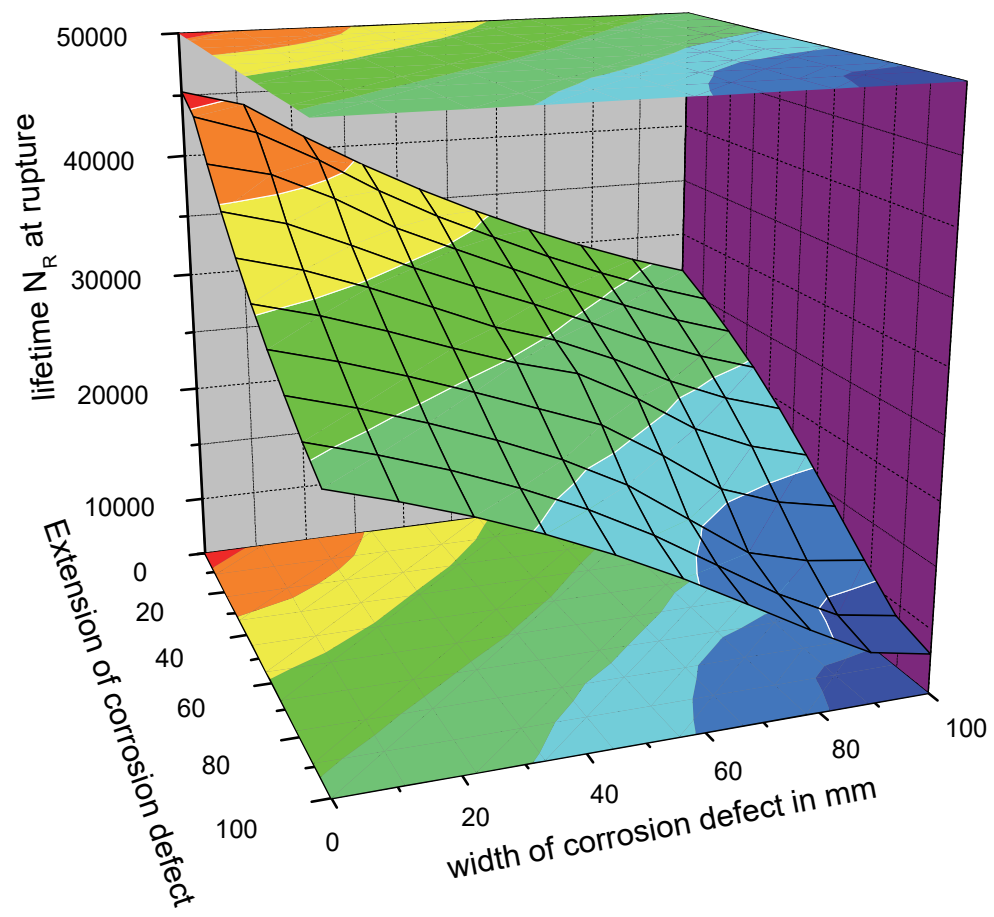

Figure 10: Number of cycles at rupture.

\section{CONCLUSION}

$\mathrm{I}$ $\mathrm{n}$ this study, a method was developed to highlight the weaknesses of the ASME / B31G method using the concept of damage mechanics. The prediction of damage initiation from an existing corrosion defect of steel pipes has been investigated using numerical approach. A constitutive coupled behaviour-damage based on the concept of effective stress and on finite element method to determine a critical value of stress at the vicinity of corrosion defect. A Finite element simulation is based on the steel elastoplastic constitutive law and on the chosen mesh for a good relative convergence accuracy of the damage values. For the depth of defects does not exceed $10 \%$ of the pipe thickness, we have shown that defects can resist to the hydrostatic pressure test or a constant service pressure without damaging the pipe. However, these defects do not resist to pressure variations, which may generate a phenomenon of fatigue causing a failure of pipe. Therefore, failures can occur for corrosion defects when the depth value reached $10 \%$ of the pipe thickness, while the ASME / B31G method states that no rupture of pipe occur in this case.

However, it has been shown that the concept of damage mechanics allows determining the optimum depth defect in order to predict the failure of pipe.

\section{REFERENCES}

[1] ASME B31G (2009): Manual for Determining the Remaining Strength of Corroded Pipelines [S]. American Society of Mechanical Engineers, New York.

[2] Caligiuri, R. D. (2015). Critical crack path assessments in failure investigations, Frattura ed Integrità Strutturale, 34 125-132; DOI: 10.3221/IGF-ESIS.34.13

[3] Zampieri, P. Curtarello, A.Pellegrino, C. Maiorana, E. (2018). Fatigue strength of corroded bolted connection Frattura ed Integrita Strutturale, 12 (43), pp. 90-96. DOI: 10.3221/IGF-ESIS.43.06 
[4] Zampieri, P. Curtarello, A. Maiorana, E .Pellegrino, C. (2017).Numerical analyses of corroded bolted connections. 2nd International Conference on Structural Integrity, ICSI 2017, 4-7 September 2017, Funchal, Madeira, Portugal, Procedia Structural Integrity 5, pp. 592-599.

[5] Testa, G., Bnora, N., Gentile, D., Ruggiero, A, Iannitti, G. (2017). Strain capacity assessment of API X65 steel using damage mechanics. Frattura ed Integrità Strutturale, 42, pp. 315-327; DOI: 10.3221/IGF-ESIS.42.33

[6] Terán, G. Capula-Colindres, S. Velázquez, J.C. Fernández-Cueto, M. J. Angeles-Herrera, D.Héctor HerreraHernández. (2017). Failure Pressure Estimations for Pipes with Combined Corrosion Defects on the External Surface: A Comparative Study. Int. J. Electrochem. Sci., 12, pp. 10152 - 10176, DOI: 10.20964/2017.11.86.

[7] ANSYS: http://www.ansys.com/products/academic.

[8] Benzerga, D. (2015).Burst pressure estimation of corroded pipeline using damage mechanics, Mmssd, ISBN 978-3319-14531-0. DOI: 10. 1007/978-3-319-14532-7 springer.

[9] Saheya, B., Guo-qing, C., Yun-kang, S., Cai-ying, W. (2016). A new newton-like method for solving nonlinear equations, Springer Plus 5, pp. 1269.DOI 10.1186/s40064 01629097.

[10] António .A. F, Abílio M. P., Renato N.J. (2018). Monotonic and ultra-low-cycle fatigue behaviour of pipeline steels experimental and numerical approaches, pp. 36-120.DOI.org/10.1007/978-3-319-78096-2_2.

[11] ACPRE: (1996). Risk Management Program Standard, for use in the Pipeline Risk Management Demonstration Program Produced by the Joint Risk Management Standard Team, The Office of Pipeline Safety, American Petroleifin Institute, Interstate Natural Gas Association of America, National Association of Pipeline Safety Representatives, Gas Research Institute.

[12] Lemaitre, J. (1998). Micro-mechanics of crack imitation, I.U.T.A.M symposium on recent advances in nonlinear fracture mechanics, PASADENA California (U.S.A) - march.

[13] Lemaitre, J., Doghri, I. (1994). Damage 90: a post processor for crack initiation, Comput. Methods Appl. Mech. Eng.115, pp. 197-232.

[14] Lemaitre, J. (1993). Mécanique des solides déformables et endommage ables, Cours de D.E.A, Cachan, Edition October.

[15] Artioli, E., Auricchio, F., Beirão da Veiga, L. (2007). Second-order accurate integration algorithms for Von-Mises plasticity with a nonlinear kinematic hardening mechanism, Comput. Methods Appl. Mech. Engrg. 196, pp. 18271846.

[16] Benallal, A. Billardon, R. Doghri, I. (1988). An integration algorithm and the corresponding consistent tangent operator for fully coupled elastoplastic and dam- age equations, Comm. Appl. Numer. Methods 4, pp. 731-740.

[17] Courtney, R. (2012-2013). Numerical Methods for Solving Systems of Nonlinear Equations, A project submitted to the Department of Mathematical Sciences in conformity with the requirements for Math 4301 (Honour's Seminar), Lakehead University Thunder Bay, Ontario, Canada. 